\title{
Productivity Growth in Indian Oil Refineries: Efficiency Improvement or Technical Improvement
}

\author{
*Dr.A.Vijayakumar **P.Gomathi \\ *Associate Professor in Commerce, Erode Arts and Science College, Erode. \\ **Part-Time Ph.D Scholar, Assistant Professor in Commerce, STC College, Pollachi
}

\begin{abstract}
Productivity acts as a parameter to measure the efficiency of an industry. Productivity studies help to estimate the measure of protection to be granted to an industry. An increase in the level of productivity reflects an increase in the efficiency of inputs. In this study DEA(Data Envelopment Analysis)- Malmquist Index was used to identify the sources of Total Factor Productivity growth which will help the policy makers to know the performance of industry and take steps to increase productivity and efficiency in selected oil refineries in India. The inference made in the analysis reveals that all the companies recorded productivity improvement and a similar trend was noticed in the technical change also. In efficiency change, there are four companies that reported negative efficiency change during the study period. On the whole the impact of economic reforms on the Total Factor Productivity at the aggregate level was impressive as the TFP change was estimated at 8.6 per cent for all the companies. It is evident from the results that the free economic environment has benefited only in technology not in efficiency of Indian manufacturing industry.
\end{abstract}

Key words: Productivity, Indian Oil Refinery, Malmquist Index, Data Envelopment Analysis, Total Factor Productivity and Efficiency Change and Technical Change

Productivity Growth in Indian Oil Refineries : Efficiency Improvement or Technical Improvement

Productivity involves a comparison between the quantity of goods and service produced and the quantity of resource employed in turning out these goods and services. When the same resources that were employed in the past now produce more than they did before, one may say that productivity has increased. Productivity and profitability are the important concepts and measures describing the performance and success of a firm. Increase in productivity decreases the costs per unit produced and leads to better profitability. The main difference between the concepts of profitability and productivity is that profitability deals with costs and revenues whereas productivity deals with the amounts of input and output. The concept of factor productivity gives the contribution which one or all used factors make to production. The study of factor productivity is an important aspect of the analysis of development since it quantifies the contribution of the different factors of production. Higher levels of growth can be attained through better utilization of available resources i.e., capital and labour. It is the most useful measurement of the variations of productivity in time. It is the best means of evaluating the contribution of the various factors. Therefore, the study of factor productivity has particular significance in the formulation of policies at the state as well as national levels.

The study of productivity of the factors of production is important in view of the limited availability of the factors of production, particularly capital. Depending upon the nature of the product and the process of production, different industries employ different combinations of the factor inputs. In the labour- intensive industries using unskilled and / or semi- skilled workers with a relatively low wage rate, the emphasis is on increasing the productivity of capital. On the other hand, in the capital- intensive industries, the prime concern is to increase labour productivity. As such, there are considerable variations in the factor intensive across different industries as well as different states. Therefore, when the objective is to examine variations in the levels of productivity, the concept of total productivity rather than partial productivity becomes more relevant.

\section{Review of Literature}

There are several factors affecting productivity such as level of technology and socio-demographic changes. (Bhatia, 1990) ${ }^{\mathrm{i}}$. He argued that lower level of technology and unstable socio-demographic changes were causing low productivity in India as compared to the United States and the United Kingdom. A large body of literature has looked into the relative productivity of locally owned firms versus foreign owned firms, with the objective of formulating more effective policies with regards to Foreign Direct Investment (FDI). Along such lines, Asheghian (1982) attempted to evaluate the comparative efficiency of foreign firms and local firms in Iran in an effort to present intra-firm efficiency comparisons (based on three indices of efficiency including TFP). The study concluded that international joint-venture firms have been more efficient than locally owned firms. Chung et al. (2006) found out that the productivity of local suppliers with linkages to Japanese 
transplants did not grow faster than that of unaffiliated suppliers, and concluded that there was no evidence of direct technology transfer positively affecting US suppliers' productivity during the study period. Basti and Akin (2008) compared the productivity of domestic and foreign firms operating in Turkey. The results of the study indicated that there were no differences in terms of productivity of domestic and foreign firm.

The evidence on Total Factor Productivity Growth (TFPG) in India as brought out by a number of studies has been quite varied. Ahluwalia (1991) observed a decline in Total Factor Productivity (TFP) at the rate of 0.3 per cent per annum over the period from 1965-66 to 1979-80. The study established a negative relationship between total factor productivity growth and a Chenery measure of import substitution. Mitra (1999) studied total factor productivity of 15 major states and recorded higher productivity growth from 198586 to 1992-93 when compared to the period from 1976-77 to 1984-85. Timmer (1999) in his study showed that TFP growth of Indonesian manufacturing industries accounted for only 22 per cent of the output growth. Analysis of Goldar and Kumari (2003) revealed that underutilization of industrial capacity was an important cause of the productivity slowdown.

Subsequently, several studies have been undertaken to understand the impact of economic reforms on manufacturing productivity. Ramaswamy (1999) studied the comparative performance of Indian manufacturing industries during relatively recent periods of domestic regulation and deregulation of plant entry. The growth of labour and Total Factor Productivity (TFP) was observed to be higher during the deregulation period. Fujita (1994) reported that the liberalization policies improved the productivity of the manufacturing industry and the improvement of the productivity led to the expansion of the export of manufactured products. Ray (2002) analyzed the impact of economic reforms of Indian manufacturing sector and stated that annual growth rate of productivity has been higher in the post-reform period than in the pre-reform year. Unel(2003) studied the productivity growth of Indian manufacturing sector and concluded that Total Factor Productivity Growth (TFPG) in aggregate manufacturing and many sub-sectors accelerated after the 1991 reforms. Kim and Park (2006) observed that productivity gains in Korean manufacturing sector were due to efficiency improvement rather than technical progress.

Several studies have been conducted in foreign countries to estimate Total Factor Productivity Growth using Malmquist Productivity Index. There are a few studies on the manufacturing sector of Pakistan which used macro level data, variables and different approaches to measure the Total Factor Productivity like Mahmood et al. (2007). There are some studies on manufacturing sector of Pakistan which include Mahmood et al. (2007) who estimated the efficiency of large scale manufacturing industries in Pakistan using production frontier approach. Burki and Khan (2005) analyzed the implications of allocative efficiency on resource allocation and energy substitutability for large scale manufacturing units. These studies have used aggregate data of the sectors and economy. All these studies used data up to 2001. Diaz and Sanchez (2008) analyzed the performance of the small and medium Spanish manufacturing firms and focused on the technical inefficiency and its determinants for these firms using stochastic frontier production function. The findings of the results suggested that small and medium firms are more efficient than large firms. Fare, Grosskopf and Margaritis (2001) analyzed the relative trend in the Total Factor Productivity in Australia and New Zealand for the manufacturing sector during the period from 1986 to 1999. New Zealand performed better than Australia in terms of total factor productivity for manufacturing sector.

The variations in the findings of these studies may be due to the differences in the methodology adopted by them. For example, some studies estimated productivity growth for the aggregate manufacturing sector or sub-sectors. The differences in the estimation procedure may also give rise to differences in the productivity estimates. For example, some studies applied production function, while some other applied cost function. The previous studies revealed that Malmquist Productivity Index has been mostly applied in foreign countries. However, the focus on Indian manufacturing industries and in particular, Oil Refinery Industry has got no place. Therefore, the present study applies a Data Envelopment Analysis model of Malmquist Index of productivity used to decompose TFP growth in Indian Oil Refinery industry between 1994-95 and 2008-09, into two components such as efficiency change and technical change.

Statement of the Problem

Productivity acts as a parameter to measure the efficiency of an industry. Productivity studies help to estimate the measure of protection to be granted to an industry. An increase in the level of productivity reflects an increase in the efficiency of inputs. Here, DEA(Data Envelopment Analysis)- Malmquist Index was used to identify the sources of Total Factor Productivity growth which will help the policy makers to know the performance of industry and take steps to increase productivity and efficiency. With the available literature there are no reported studies related to this industry using Malmquist Productivity Index. So, in this study an attempt has been made to measure sources of productivity growth by using the DEA- Malmquist Productivity Index in selected oil refineries in India. 


\section{Selection of Oil Refinery Industry}

The Indian oil and gas sector is one of the six core industries in India and has very significant forward linkages with the entire economy. Petroleum Refining Industry is a generator of fuel required for energy purposes in all sorts of industry. Hence, this industry can be regarded as the heart of economy. Petroleum and its different products have a very dominant role not only in our society but also in the overall development process. It is a source of energy for domestic, industrial, agricultural and transport services and as feed stock for fertilizer, chemical and other industries. It has also created an impetus for allied sectors such as engineering, procurement, construction firms, project management consultancy firms and other such service providers. The rapidly growing number of petroleum and petrochemicals industries in the country during the last three decades have generated considerable employment at all levels. The petroleum sector in India is particularly favorable to foreign investment because the industry is one of the fastest growing segments, and it has shown a staggering growth rate of around 13 per cent in the recent past. Apart from the tremendous growth rate in the Indian petroleum industry today, it also boasts of technology of international standards, easy availability of infrastructure at very cheap rates, high demand for petroleum products, and increased spending habits of the middle-class people. All these factors make investments in the Indian petroleum sector an attractive proposition for foreign investors. India is the $22^{\text {nd }}$ largest producer in the world and fifth largest petroleum refining country with a share of 3 per cent of global capacity. The expansion of Indian petroleum retail market is triggered by the growth in automobile sales that has resulted in major foreign investments. The growth is estimated to sustain and the market is likely to expand further by 20 million every year till 2030, placing India at the world map in terms of being the biggest automobile market. This has encouraged the researcher to analyze the productivity performance of Oil Refinery Industry in India.

\section{Statement of the Problem}

Productivity acts as a parameter to measure the efficiency of an industry. Productivity studies help to estimate the measure of protection to be granted to an industry. An increase in the level of productivity reflects an increase in the efficiency of inputs. Here, DEA(Data Envelopment Analysis)- Malmquist Index was used to identify the sources of Total Factor Productivity growth which will help the policy makers to know the performance of industry and take steps to increase productivity and efficiency. With the available literature there are no reported studies related to this industry using Malmquist Productivity Index. So, in this study an attempt has been made to measure sources of productivity growth by using the DEA- Malmquist Productivity Index in selected oil refineries in India.

\section{Sampling Design}

Keeping in view of the scope of the study, the oil refineries operating in India were considered for the study. It was decided to include all the companies working in India under private sector as well as public sector from the year 1994-95. However, owing to several constraints such as non-availability of financial statements or non-working of the company in a particular year etc., it was decided to restrict the number of sample companies to seven. The Capitaline and CMIE database publish key financial data of Indian corporate sector systematically. Hence Capitaline and CMIE databases proved to be complimentary to finalize the sample for the study. The exhaustive list of oil refineries in India from Capitaline was cross checked with CMIE database to sort out companies to fit in as the sample for the study. The comprehensive list of companies prepared from the database was modified by sorting out the firms using the following criteria: which were not in operation for a year during the period of study; which were in operation but non-availability of data for the whole study period; which were merged with another company during the period of study and which were not listed in Bombay Stock Exchange. There are 20 refineries operating in India. Of these, 17 refineries are in the public sector and 3 are in private sector. Out of the oil refineries operating in India, only 15 companies' data are available in the databases. Among the 15 companies, 9 companies are listed in a stock exchange, and 2 of them are merged companies, and so the remaining seven companies have been taken for the present study. The selected companies includes in the present study are: Indian Oil Corporation Ltd(IOCL), Bharat Petroleum Corporation Ltd(BPCL), Hindustan Petroleum Corporation Ltd(HPCL), Mangalore Refinery and Petrochemicals Ltd(MRPL), Essar Oil Ltd(EOL), Chennai Petroleum Corporation Ltd(CPCL) and Reliance Industries Ltd(RIL). The period from 1996-97 to 2010-11 is selected for the study of selected Indian oil refineries. This 15-year period is chosen in order to have a fairly long, cyclically well balanced period, for which reasonably homogeneous, reliable and up-to-date data would be available.

\section{Source of Data}

The study is mainly based on secondary data. The data analyzed and interpreted in this study related to all companies selected are collected from "Capitaline" and "PROWESS" databases, which are the most reliable on the empowered corporate database of Bombay Stock Exchange and Centre for Monitoring Indian Economy 
(CMIE) respectively. Besides Capitaline and PROWESS databases, relevant secondary data have also been collected from BSE Stock Exchange Official Directory, CMIE Publications, Annual Survey of Industry, Business Newspapers, Reports on Currency and Finance, Libraries of various research institutions and the Internet. As the study required a variety of data, various websites have been comprehensively searched.

\section{Data Analysis - Malmquist TFP Index}

DEA- Malmquist Index is used to calculate the total factor productivity growth in selected oil refineries in India. The Malmquist TFP Index measures changes in total output relative to input. It is a suitable methodology because of the following reasons. First, the Data Envelopment Analysis approach is an improvement over translog index approach. In translog approach technical inefficiency is ignored and it calculates only technical change which is wrongly interpreted as TFP growth, while in the literature of productivity, TFPG is composed of technical change and technical efficiency. Second, DEA also identifies the sources of TFP growth which will help the policy makers to indentify the specific source of low TFP growth. Another advantage of non-parametric nature of DEA is that it reveals the best practice frontier rather central tendency properties of frontier. In DEA, there is also no need to estimate any production function. This Malmquist Productivity Index can be decomposed into efficiency change, technical change and Total Factor Productivity Growth. TFPG is the geometric mean of efficiency change and technical change.

The measurement of the Malmquist Productivity Index is based on distance functions. For simplicity, $z^{t}=\left(x^{t}, y^{t}\right)$ and $z^{t+1}=\left(x^{t+1}, y^{t+1}\right)$, where $x^{t}$ is the vector of inputs used in production and $y^{t}$ is the vector of outputs. Now, for each time period $t=1, \ldots . . T$, the output distance function is defined as follows:

$$
\begin{aligned}
D^{t}(z) & =\inf \left\{\theta: y^{t} / \theta \in P^{t}(x)\right\} \\
& =\left[\sup \left\{\theta: y^{t} \in P^{t}(x)\right\}\right]^{-1}
\end{aligned}
$$

where superscript $t$ and $D^{t}$ denote that technology in period $t$ is used as the reference technology. $\theta$ is scalar, and its value is the efficiency score for each production activity. It satisfies $0<\theta \leq 1$ for a non-negative output level, with a value of 1 indicating a point of the frontier, and thus a technically efficient production activity. This output distance function is defined as the reciprocal of the maximal proportional expansion of output vector $y^{t}$ with the given input vector $\mathrm{x}^{\mathrm{t}}$ in relation to the technology at $t$.

The Malmquist Productivity Index is defined as follows:

$$
T F P=M^{t}=\frac{D^{t}\left(z^{t+1}\right)}{D^{t}\left(z^{t}\right)}
$$

This formulation is called the output-oriented Malmquist Productivity Index in period $t, M^{t}\left(z^{t+1}, z\right)$, where the technology in period ' $\mathrm{t}$ ' is the reference technology for two different pairs of outputs and inputs. Alternatively, $M^{t+1}$ can be defined where the technology in period $t+1$ is employed as the reference technology.

Consistent with the study of Fare $\boldsymbol{e t}$ al . (1994), the output-based Malmquist Productivity Index is defined as the geometric mean of two output-distance functions, in order to avoid selecting an arbitrary benchmark:

$$
\begin{aligned}
M\left(z^{t+1}, z^{t}\right) & =\left[M^{t} \cdot M^{t+1}\right]^{1 / 2} \\
& =\left[\left(\frac{D^{t}\left(z^{t+1}\right)}{D^{t}\left(z^{t}\right)}\right)\left(\frac{D^{t+1}\left(z^{t+1}\right)}{D^{t+1}\left(z^{t}\right)}\right)\right]^{1 / 2}
\end{aligned}
$$

Equation (3) can be rewritten as:

$$
M\left(z^{t+1}, z^{t}\right)=\left(\frac{D^{t+1}\left(z^{t+1}\right)}{D^{t}\left(z^{t}\right)}\right) \times\left(\frac{D^{t}\left(z^{t+1}\right)}{D^{t+1}\left(z^{t+1}\right)}\right)\left(\frac{D^{t}\left(z^{t}\right)}{D^{t+1}\left(z^{t}\right)}\right)^{1 / 2}
$$

where the ratio outside the brackets measures the change in relative efficiency between $t$ and $t+1$, and the geometric mean inside the brackets measures the shift in frontier. That is, the Malmquist productivity index can be decomposed into change in efficiency and change in technical progress.

In a previous empirical work, Fare et al. (1994) utilized non-parametric linear-programming techniques. As can be seen in (3`), four different linear programming problems must be solved: $D^{t}\left(z^{t}\right), D^{t}\left(z^{t+1}\right)$, $D^{t+1}\left(z^{t}\right)$, and $D^{t+1}\left(z^{t+1}\right)$. Calculating the Malmquist index relative to the variable returns to scale technology, $D_{j}^{t}\left(z^{t}\right)$ for each company, $j \in k=1, \ldots \ldots, K$, one of the four different linear programming problems, can be stated as: 


$$
\left[D_{j}^{t}\left(z_{j}^{t}\right)^{-1}=\max _{\theta, w} \theta_{j}\right]
$$

subject to $\theta_{j} y_{m, j}^{t} \leq \sum_{k=1}^{K} w_{k}^{t} y_{m, k}^{t} \quad \boldsymbol{m}=1, \ldots . ., M$

$$
\sum_{k=1}^{K} w_{k}^{t} x_{n, j}^{t} \leq x_{n, j}^{t} \quad \boldsymbol{n}=1, \ldots . ., N
$$

$w_{k}^{t} \geq 0 k=1, \ldots ., K$

where $n=1, \ldots, N$ are inputs, $m=1, \ldots, M$ are outputs, and $w_{k}^{t}$ is an intensity variable indicating the production intensity of a particular activity. (Here, each company is an activity). These intensity variables are used as weights in taking convex combinations of the observed outputs and inputs in both (4a) and (4b). From Equation 4 , the reciprocal of the output distance function can be used to find the maximum of $\theta$, which gives the maximal proportional expansion of output given constraints (4a)-(4).

For the other distance functions, the computation of $D^{t+1}\left(z^{t+1}\right)$ is exactly the same as (4), where $t+1$ is substituted for $t$. Two other distance functions require information from two periods, $D^{t}\left(z^{t+1}\right)$ can be computed by replacing $y_{m, j}^{t}$ and $x_{n, j}^{t}$ in (4a) and (4b) with $y_{m, j}^{t+1}$ and $x_{n, j}^{t+1}$, respectively, and $D^{t+1}\left(z^{t}\right)$ is the same as $D^{t}\left(z^{t+1}\right)$, where the $t$ and $t+1$ superscripts are exchanged.

The Malmquist index of Total Factor Productivity Change (TFPCH) is the product of Technical Efficiency Change (EFFCH) and Technological Change (TECHCH).

\section{TEPCH $=$ EFFCH $*$ TECHCH}

Technical efficiency change measures the change in efficiency between current $(t)$ and next $(t+1)$ periods, while the technological change (innovation) captures the shift in frontier technology. Technological change (TECHCH) is the development of new products or the development of new technologies that allows methods of production to improve and results in the shifting upwards of the production frontier. More specifically, technological change includes both new production processes, called process innovation and the discovery of new products called product innovation. Technical efficiency change, on the other hand, can make use of existing labour, capital, and other economic inputs to produce more of the same product. Labour find new ways of doing things so that relatively minor modifications to plant and procedures can contribute to higher levels of productivity. Data envelopment analysis methodology was applied to decompose the Total Factor Productivity Growth in Indian oil refinery industry from 1995-96 to 2008-09 in to efficiency change (EFFch) and technical change (TECHch). It should be remembered that the Malmquist Productivity Index (MPI) greater than one (MPI>1) indicates productivity improvement and less than one (MPI $<1)$ refers to productivity deterioration.

\section{Results and Discussion \\ Trends in the Total Factor Productivity Growth and its Source Indian Oil Corporation Ltd}

The estimates of Malmquist Productivity Index for Indian Oil Corporation Ltd have been presented in Table 1 for the period from 1995-96 to 2008-09. The mean productivity growth of Indian Oil Corporation Ltd was 1.7 per cent for the entire period of study. Indian Oil Corporation Ltd recorded the highest positive growth at 26.8 per cent in 1998-99 and the lowest positive growth at 1.1 per cent in 2001-02. Out of fourteen years of the study period, the annual productivity growth was above the company average of 1.7 per cent in seven years and was in the range of 26.8 per cent in 1998-99 and 1.1 per cent in 2001-02. The higher productivity growth of 26.8 per cent in 1998-99 was due to both efficiency change and technical change which recorded higher growth at 4.1 per cent and 21.8 per cent respectively. In the case of efficiency change nine years have negative trends whereas five years were in technology regression and this has led to positive Total Factor Productivity Growth of Indian Oil Corporation Ltd during the period under review.

\section{Hindustan Petroleum Corporation Ltd}

The annual Total Factor Productivity Growth and its sources of Hindustan Petroleum Corporation Ltd have been presented in Table 2 . From the table it could be seen that the average productivity growth was 1.3 per cent which was contributed mainly by technical change at 2.1 per cent. The mean productivity growth was positive and the annual growth in the level of total factor productivity varied widely during the study period. 
This company witnessed positive productivity growth in six years out of the study period of fourteen years and varied between 35 per cent in 2000-01 and 1.2 per cent in 1999-00. The highest positive productivity growth of 35 per cent was recorded in 2000-01 which was contributed mainly by technical change. The least positive growth recorded at 1.2 per cent in 1999-00 was also due to no change in efficiency and 1.2 per cent in technical change respectively. The similar trend was observed in efficiency change from 1999-00 to 2004-05, thereafter it deteriorated up to 2007-08.

\section{Bharat Petroleum Corporation Ltd}

Table 3 presents estimates of Malmquist Productivity Index for Bharat Petroleum Corporation Ltd. The company has witnessed productivity growth of 0.1 per cent during the study period and contributed mainly by technical change by 0.4 per cent. Out of fourteen years of the study period, Bharat Petroleum Corporation Ltd recorded productivity improvement in eight years and productivity deterioration in the remaining years of the study period. There are wide variations in the Total Factor Productivity Growth ranging from -16.7 per cent to 15.4 per cent. The highest productivity improvement of 15.4 per cent was recorded in 2000-01 which was contributed mainly by technical change at 15.4 per cent and lowest productivity growth of 0.2 per cent was recorded in the initial year of analysis which was also contributed by the technical change by 0.2 per cent. The Bharat Petroleum Corporation Ltd experienced productivity decline in six years ranging from -16.7 per cent in 2001-02 to -1 per cent in 2004-05. The highest negative productivity growth of 16.7 per cent in 2001-02 was mainly due to greater technology decline to the extent of 16.7 per cent and due to no change in efficiency. The least productivity decline was noticed at 1 per cent in 2004-05 which was due to deterioration in efficiency change at -4.9 per cent and technical change at -8.7 per cent. In the case of efficiency change, there is a uniform pattern from 1995-96 to 2001-02. In spite of the negative efficiency change, there was a productivity improvement by 0.1 per cent for the entire study period in Bharat Petroleum Corporation Ltd.

\section{Mangalore Refinery and Petrochemicals Ltd}

The mean and the annual growth in the Total Factor Productivity with its components efficiency change and technical change of Mangalore Refinery and Petrochemicals Ltd have been reported in Table 4. From the table it could be noted that the mean Total Factor Productivity was estimated at 15.5 per cent. Mangalore Refinery and Petrochemicals Ltd marked total factor productivity improvement and deterioration in three years out of a study period of fourteen years. It witnessed the highest Total Factor Productivity gain by 78.6 per cent in 1998-99 and the technical change contributed for the higher productivity growth. The lowest productivity growth was estimated at 0.3 per cent in 2001-02. The productivity losses in three years was - 27.8 per cent in 2007-08, - 24.7 per cent in 1996-97 and - 7.7 per cent in 2000-01. Similar results were evidenced in technical change also. Further, the table reveals that positive technical progress and no change in efficiency leads to improvement in productivity.

\section{Chennai Petroleum Corporation Ltd}

Table 6.5 reports the productivity growth and the major sources of such growth for the Chennai Petroleum Corporation Ltd during the study period. The company has witnessed positive productivity growth of 12.1 per cent contributed mainly by technical change by 11 per cent. There was positive productivity growth in ten years out of fourteen years considered in the study and there was productivity deterioration in the remaining four years. The productivity growth varied in this study period within the range of 59.2 per cent in 2004-05 and contributed both by efficiency change ( 46.5 per cent) and technical change ( 8.6 per cent). The lowest positive productivity growth was noticed at 3.9 per cent in 2006-07 contributed mainly by the technical change (3.9 per cent). The Chennai Petroleum Corporation Ltd witnessed negative productivity growth, the highest productivity deterioration marked at -32.9 per cent in 1995-96 due to efficiency change which declined to -43.7 per cent. In the case of efficiency change, there was positive change in eleven years out of fourteen years and similar trend was observed in technical change also.

\section{Essar Oil Ltd}

Table 6 reports the estimation of total factor productivity growth and its components of the Essar Oil Ltd for the study period with the mean value of 24.1 per cent. The analysis clearly shows that there were positive levels of productivity growth in seven years out of fourteen years. This company marked the highest positive growth in 2007-08 explained more by the improvement in efficiency change, despite a fall in the technical change. The productivity growth was noticed to be the least at 6.4 per cent in 1998-99 contributed by technical change at 37 per cent. This increase in the productivity growth was accounted by a greater fall in the efficiency change by -22.4 per cent. There was productivity regression in the seven years ranging from -63.1 per cent in 2005-06 and -3.6 per cent in 1999-00. The higher negative productivity growth was due to both the factors namely efficiency change and technical change, while efficiency change declined by -20.2 per cent, the 
technical change fell by -3.5 per cent. The fall in these two sources together pulled down the productivity growth of this company by -23 per cent in 1997-98. The decline in the efficiency change by -21.9 per cent and positive technical change by 17.8 per cent were the reasons for the relatively lower negative productivity growth at -8 per cent when compared to 1997-98. With these mixed estimates, the average productivity growth was estimated to be positive at 24.1 per cent due to the significant increase in both the factors like efficiency change by 13 per cent and technical change by 9.8 per cent during the period under review.

\section{Reliance Industries Ltd}

Table 7 presents the estimates of Malmquist Productivity Index of the Reliance Industries Ltd during the study period from 1995-96 to 2008-09. From the table it could be noted that the mean productivity growth of this company was estimated at 7.1 per cent and this productivity improvement was mainly due to improvement in technical change at 15.1 per cent while efficiency change by 6.9 per cent. Among the years, the company witnessed positive productivity growth in nine years out of fourteen years and was above the mean value of 7.1 in seven years. The positive productivity was in the range of 53.8 per cent in 1999-00 and 2.9 per cent in 2002-03. The higher positive Total Factor Productivity Growth was explained both by efficiency change and technical change. While the efficiency change increased by 48.5 per cent and technical change improved by 3.6 per cent, it was again the technical change (17.6 per cent) that was more responsible for the positive growth of productivity of 11.8 per cent estimated in 2004-05 despite a fall in the efficiency change by -4.9 per cent. The Reliance Industries Limited witnessed productivity deterioration in five years of the study period. The negative productivity growth varied between 34.4 per cent in 1996-97 and 4.1 per cent in 2006-07. The negative growth in the Total Factor Productivity was primarily due to greater fall in the efficiency change by -28.8 per cent irrespective of an improvement in the technical change to the extent of 30.9 per cent estimated in 2008-09. The positive and comparatively higher Total Factor Productivity Growth witnessed in the Reliance Industries Ltd was contributed by technical change when compared to efficiency change.

\section{Estimates of Annual Means of Total Factor Productivity Growth in Oil Refinery Industry}

Table 8 presents the result of annual means of Indian oil refinery industry from 1995-96 to 2008-09 and there was an increase in the Total Factor Productivity Growth by 8.6 per cent for the entire industry. This significant growth was contributed both by efficiency change by 0.3 per cent and technical change by 8.2 per cent. From the result it could be inferred that it was the positive productivity growth in Indian Oil Refinery industry. During the period from 1995-96 to 2008-09 the Total Factor Productivity witnessed a wide change. It was negative at 1.6 per cent in 1995-96 to 14.3 per cent in 2008-09. The Indian oil refinery industry evidenced the highest productivity growth at 35.6 per cent in 2007-08 contributed mainly by efficiency change to the extent of 42.3 per cent.

There were also productivity deterioration in four years out of the fourteen years of study period ranging from -19.4 per cent in 1996-97 to -1.6 per cent in 1995-96. The productivity decline in 1996-97 was due to both factors, efficiency change and technical change particularly the efficiency which declined productivity growth by -14.2 per cent. From the table, it could be noticed that efficiency change was below one in many of the years which could be the reason for productivity deterioration or for slow productivity growth in Indian oil refinery industry. There was an improvement in technical progress as a result of the reform process initiated by the government. As a consequence, the Indian oil refinery industry could adopt new and innovative methods of economic reforms of production. This new methodology must be fully utilized to convert into productivity gain, but the slow growth in the efficiency change could not convert the technical progress into productivity gain in the Indian oil refinery industry.

\section{Estimates of Company Means of Total Factor Productivity Growth in oil refinery industry}

The comparative results of individual companies in terms of productivity are presented in Table 9 which explain the Total Factor Productivity change for all the companies and provide comprehensive understanding about the performance of different companies. The industry as a whole witnessed significant positive productivity growth of 8.6 per cent and this was mainly contributed by technical change by 8.2 per cent rather than efficiency by 0.3 per cent. But there were wide fluctuations in the TFPG across the study period. The TFPG was in the range of -32.9 in 1995-96 and a positive high growth of 59.2 per cent in 2004-05. All the companies have recorded productivity improvement over the years. The companies which recorded positive and higher TFP growth experienced higher technical change as the source of such productivity growth. The highest annual productivity growth has been recorded by Essar Oil Ltd at 24.1 per cent followed by Mangalore Refinery and Petrochemicals Ltd (15.5 per cent) and Chennai Petroleum Corporation Ltd (12.1 per cent). The productivity growth has been low in Bharat Petroleum Corporation Ltd ( 0.1 per cent). This positive productivity improvement was due to the technological progress in all companies during the period under review. In the case of efficiency change, four out of seven companies recorded negative efficiency change from 1995-96 to 
2008-09. There is no change in efficiency found in Mangalore Refinery and Petrochemicals Limited while Essar Oil Ltd and Chennai Petroleum Corporation Ltd witnessed efficiency improvement of 13 per cent and 1 per cent respectively.

\section{Conclusion}

The inference made in the analysis reveals that all the companies recorded productivity improvement and a similar trend was noticed in the technical change also. In efficiency change, there are four companies that reported negative efficiency change during the study period. On the whole the impact of economic reforms on the Total Factor Productivity at the aggregate level was impressive as the TFP change was estimated at 8.6 per cent for all the companies. It is evident from the results that the free economic environment has benefited only in technology not in efficiency of Indian manufacturing industry. The Government of India invited foreign companies only to meet the investment requirements, to facilitate the transfer of technologies through direct and indirect spillovers to the domestic industries and to make the domestic firms more competitive and productive. But in reality, the domestic firms could not benefit much out of these reform measures. Efficiency change has been identified as a deteriorating factor for productivity change in Indian oil refinery industry both at the aggregate and company level. While the TFPG was significant at the industry level, the companies witnessed mixed estimates due to company's specific factors. Therefore, the concept of homogeneity cannot apply to the industry as the companies widely differ in terms of efficiency change which was responsible for the productivity growth. There was higher inflow of capital and the greater improvements in the technological changes as a consequence of economic reforms in the country. But these advancements must be fully utilized by the work force to covert the innovations into productivity gains. The study suggests that while formulating policy for an industry, this heterogeneity at the company level must be considered for the effective use of factor inputs.

\section{References}

[1]. Asheghian, Parviz (1982). "Comparative Efficiency of Foreign Firms and Local Firms in Iran”, Journal of International Business Studies, 13(3) : $\quad$ 113-120.

[2]. Basti, Y. and Akin, A. (2008). "The Comparative Productivity of the Foreign-Owned Companies in Turkey: A Malmquist Productivity Index Approach", International Research Journal of Finance and Economics, $22: 1450-2887$.

[3]. Basti, Y. and Akin, A. (2008). "The Comparative Productivity of the Foreign-Owned Companies in Turkey: A Malmquist Productivity Index Approach", International Research Journal of Finance and Economics, 22 : 1450-2887.

[4]. Chung, Wilbur, W. Michell and B. Yeung (2003). "Foreign Direct Investment and Host Country Productivity: The American Automotive Component Industry in the 1980s", Journal of International Business Studies, 34(2) : 199-218.

[5]. Das, Kusum Deb (2004). "Manufacturing Productivity Under Varying Trade Regimes, 1980-2000", Economic and Political Weekly, 39:423-433.

[6]. Kim. Taegi and Changsuh. Park (2006). "Productivity Growth in Korea: Efficiency Improvement or Technical Progress?”, Applied Economics, 38: 934-954.

[7]. Fujita, N. (1994). "Liberalization Policies and Productivity in India", The Developing Economies, XXXII(4), pp. 509-24.

[8]. Timmer, M.P.(1999). "Indonesia's accent on the technology ladder: Capital stocks and total factor productivity in Indonesian manufacturing", Bulletin of Indonesian Economic Studies, 35(1) : 75-89.

[9]. Mahmood, T., Ghani, E. and Din, M. (2007). "Efficiency of Large Scale Manufacturing In Pakistan: A production Frontier Approach", Working paper, Pakistan Institute of Development Economics. p. 27.

[10]. Ramaswamy, K.V. (1999). "Productivity Growth, Protection and Plant Entry in a Deregulating Economy: The Case of India", $\underline{\text { Small }}$ Business Economics, 13:131-139.

[11]. Ray, S.C. (2002). "Did India's Economic Reforms improve Efficiency and Productivity? A Non-Parametric Analysis of the initial evidence from Manufacturing", Indian Economic Review, 37(1) : 23-57.

[12]. Goldar, B.N. and Anita Kumari (2003). "Import Liberalisation and Productivity Growth in Indian Manufacturing Industries in the 1990s", The Developing Economies, XLI(4) : 436-460.

[13]. Unel. Bulent (2003). "Productivity Trends in India's Manufacturing Sectors in the Last Two Decades", IMF Working Paper $\mathrm{WP} / 03 / 22$.

[14]. Färe, R., Grosskopf, S. and Margaritis, D. (2001).“Productivity Trends in Australian and New Zealand Manufacturing”, Australian Economic Review, 34(2) : 125-34.

[15]. Burki, A. A. and Mahmood ul Hassan, K. (2005). "Effects of Allocative Inefficiency on Resource Allocation and Energy Substitution in Pakistan's Manufacturing", Lahore University of Management Sciences. (CMER Working Paper No. 04-30).

[16]. Mahmood, T., Ghani, E. and Din, M. (2007). "Efficiency of Large Scale Manufacturing In Pakistan: A production Frontier Approach", Working paper, Pakistan Institute of Development Economics. p. 27.

[17]. Diaz, M. A. and Sanchez, R. (2008). "Firm Size and Productivity in Spain: A Stochastic frontier analysis", Small business Economics, 30, pp.315-323.

[18]. 18. Bhatia, D.P. (1990). "Misleading growth rates in the manufacturing sector of India, The

[19]. Journal of Income and Wealth, 12:222-225. 
Table 1

Sources of Productivity Growth in Indian Oil Corporation Ltd

\begin{tabular}{|c|c|c|c|}
\hline Year & EFFch & TECHch & TFPch \\
\hline $\mathbf{1 9 9 5 - 9 6}$ & 1.000 & 1.088 & 1.088 \\
\hline $\mathbf{1 9 9 6 - 9 7}$ & 1.000 & 0.976 & 0.976 \\
\hline $\mathbf{1 9 9 7 - 9 8}$ & 0.916 & 0.886 & 0.812 \\
\hline $\mathbf{1 9 9 8 - 9 9}$ & 1.041 & 1.218 & 1.268 \\
\hline $\mathbf{1 9 9 9 - 0 0}$ & 0.910 & 1.013 & 0.922 \\
\hline $\mathbf{2 0 0 0 - 0 1}$ & 0.867 & 1.300 & 1.127 \\
\hline $\mathbf{2 0 0 1 - 0 2}$ & 1.175 & 0.860 & 1.011 \\
\hline $\mathbf{2 0 0 2 - 0 3}$ & 0.793 & 1.193 & 0.946 \\
\hline $\mathbf{2 0 0 3 - 0 4}$ & 1.092 & 0.959 & 1.047 \\
\hline $\mathbf{2 0 0 4 - 0 5}$ & 0.961 & 0.929 & 0.892 \\
\hline $\mathbf{2 0 0 5 - 0 6}$ & 0.993 & 1.096 & 1.088 \\
\hline $\mathbf{2 0 0 6 - 0 7}$ & 0.946 & 1.083 & 1.024 \\
\hline $\mathbf{2 0 0 7 - 0 8}$ & 0.976 & 1.171 & 1.143 \\
\hline $\mathbf{2 0 0 8 - 0 9}$ & 0.981 & 1.004 & 0.985 \\
\hline Mean & $\mathbf{0 . 9 7 1}$ & $\mathbf{1 . 0 4 8}$ & $\mathbf{1 . 0 1 7}$ \\
\hline
\end{tabular}

Note: - All Malmquist index averages are geometric means.

EFFch-Efficiency change, TECHch-Technological progress, TFPch-Total Factor

Productivity change.

Source: Computed

Table 2

Sources of Productivity Growth in Hindustan Petroleum Corporation Ltd

\begin{tabular}{|c|c|c|c|}
\hline Year & EFFch & TECHch & TFPch \\
\hline $\mathbf{1 9 9 5 - 9 6}$ & 0.997 & 0.990 & 0.987 \\
\hline $\mathbf{1 9 9 6 - 9 7}$ & 0.928 & 0.916 & 0.850 \\
\hline $\mathbf{1 9 9 7 - 9 8}$ & 1.068 & 0.858 & 0.916 \\
\hline $\mathbf{1 9 9 8 - 9 9}$ & 1.064 & 1.209 & 1.286 \\
\hline $\mathbf{1 9 9 9 - 0 0}$ & 1.000 & 1.012 & 1.012 \\
\hline $\mathbf{2 0 0 0 - 0 1}$ & 1.000 & 1.350 & 1.350 \\
\hline $\mathbf{2 0 0 1 - 0 2}$ & 1.000 & 0.858 & 0.858 \\
\hline $\mathbf{2 0 0 2 - 0 3}$ & 1.000 & 1.162 & 1.162 \\
\hline $\mathbf{2 0 0 3 - 0 4}$ & 1.000 & 0.926 & 0.926 \\
\hline $\mathbf{2 0 0 4 - 0 5}$ & 1.000 & 0.911 & 0.911 \\
\hline $\mathbf{2 0 0 5 - 0 6}$ & 0.984 & 0.974 & 0.959 \\
\hline $\mathbf{2 0 0 6 - 0 7}$ & 0.878 & 1.083 & 0.951 \\
\hline $\mathbf{2 0 0 7 - 0 8}$ & 0.974 & 1.171 & 1.140 \\
\hline $\mathbf{2 0 0 8 - 0 9}$ & 1.011 & 1.004 & 1.015 \\
\hline Mean & $\mathbf{0 . 9 9 2}$ & $\mathbf{1 . 0 2 1}$ & $\mathbf{1 . 0 1 3}$ \\
\hline
\end{tabular}

Note: - All Malmquist index averages are geometric means.

EFFch-Efficiency change; TECHch-Technological progress ; TFPch-Total Factor

Productivity change.

Source: Computed 
Productivity Growth in Indian Oil Refineries : Efficiency Improvement or Technical Improvement

Table 3

Sources of Productivity Growth in Bharat Petroleum Corporation Ltd

\begin{tabular}{|c|c|c|c|}
\hline Year & EFFch & TECHch & TFPch \\
\hline $\mathbf{1 9 9 5 - 9 6}$ & 1.000 & 1.002 & 1.002 \\
\hline $\mathbf{1 9 9 6 - 9 7}$ & 1.000 & 0.893 & 0.893 \\
\hline $\mathbf{1 9 9 7 - 9 8}$ & 1.000 & 0.852 & 0.852 \\
\hline $\mathbf{1 9 9 8 - 9 9}$ & 1.000 & 1.139 & 1.139 \\
\hline $\mathbf{1 9 9 9 - 0 0}$ & 1.000 & 1.088 & 1.088 \\
\hline $\mathbf{2 0 0 0 - 0 1}$ & 1.000 & 1.154 & 1.154 \\
\hline $\mathbf{2 0 0 1 - 0 2}$ & 1.000 & 0.833 & 0.833 \\
\hline $\mathbf{2 0 0 2 - 0 3}$ & 0.926 & 1.123 & 1.040 \\
\hline $\mathbf{2 0 0 3 - 0 4}$ & 0.951 & 0.913 & 0.869 \\
\hline $\mathbf{2 0 0 4 - 0 5}$ & 1.068 & 0.927 & 0.990 \\
\hline $\mathbf{2 0 0 5 - 0 6}$ & 0.973 & 0.958 & 0.932 \\
\hline $\mathbf{2 0 0 6 - 0 7}$ & 1.022 & 1.083 & 1.107 \\
\hline $\mathbf{2 0 0 7 - 0 8}$ & 0.971 & 1.171 & 1.137 \\
\hline $\mathbf{2 0 0 8 - 0 9}$ & 1.064 & 1.004 & 1.068 \\
\hline Mean & $\mathbf{0 . 9 9 8}$ & $\mathbf{1 . 0 0 4}$ & $\mathbf{1 . 0 0 1}$ \\
\hline
\end{tabular}

Note: - All Malmquist index averages are geometric means.

EFFch-Efficiency change;TECHch-Technological progress; TFPch-Total Factor Productivity change.

Source: Computed

Table 4

Sources of Productivity Growth in Mangalore Refinery and

Petrochemicals Ltd

\begin{tabular}{|c|c|c|c|}
\hline Year & EFFch & TECHch & TFPch \\
\hline $\mathbf{1 9 9 5 - 9 6}$ & 1.000 & 1.298 & 1.298 \\
\hline $\mathbf{1 9 9 6 - 9 7}$ & 1.000 & 0.753 & 0.753 \\
\hline $\mathbf{1 9 9 7 - 9 8}$ & 1.000 & 1.296 & 1.296 \\
\hline $\mathbf{1 9 9 8 - 9 9}$ & 1.000 & 1.786 & 1.786 \\
\hline $\mathbf{1 9 9 9 - 0 0}$ & 1.000 & 1.295 & 1.295 \\
\hline $\mathbf{2 0 0 0 - 0 1}$ & 1.000 & 0.923 & 0.923 \\
\hline $\mathbf{2 0 0 1 - 0 2}$ & 1.000 & 1.003 & 1.003 \\
\hline $\mathbf{2 0 0 2 - 0 3}$ & 1.000 & 1.581 & 1.581 \\
\hline $\mathbf{2 0 0 3 - 0 4}$ & 1.000 & 1.389 & 1.389 \\
\hline $\mathbf{2 0 0 4 - 0 5}$ & 1.000 & 1.044 & 1.044 \\
\hline $\mathbf{2 0 0 5 - 0 6}$ & 1.000 & 1.178 & 1.178 \\
\hline $\mathbf{2 0 0 6 - 0 7}$ & 1.000 & 1.108 & 1.108 \\
\hline $\mathbf{2 0 0 7 - 0 8}$ & 1.000 & 0.722 & 0.722 \\
\hline $\mathbf{2 0 0 8 - 0 9}$ & 1.000 & 1.287 & 1.287 \\
\hline Mean & $\mathbf{1 . 0 0 0}$ & $\mathbf{1 . 1 5 5}$ & $\mathbf{1 . 1 5 5}$ \\
\hline
\end{tabular}

Note: - All Malmquist index averages are geometric means.

EFFch-Efficiency change, TECHch-Technological progress, TFPch-Total Factor Productivity change.

Source: Computed 
Table 5

Sources of Productivity Growth in Chennai Petroleum Corporation Ltd

\begin{tabular}{|c|c|c|c|}
\hline Year & EFFch & TECHch & TFPch \\
\hline $\mathbf{1 9 9 5 - 9 6}$ & 0.563 & 1.191 & 0.671 \\
\hline $\mathbf{1 9 9 6 - 9 7}$ & 1.239 & 1.023 & 1.267 \\
\hline $\mathbf{1 9 9 7 - 9 8}$ & 1.041 & 0.921 & 0.959 \\
\hline $\mathbf{1 9 9 8 - 9 9}$ & 1.070 & 1.315 & 1.407 \\
\hline $\mathbf{1 9 9 9 - 0 0}$ & 1.097 & 1.014 & 1.112 \\
\hline $\mathbf{2 0 0 0 - 0 1}$ & 1.021 & 1.410 & 1.440 \\
\hline $\mathbf{2 0 0 1 - 0 2}$ & 1.330 & 0.888 & 1.181 \\
\hline $\mathbf{2 0 0 2 - 0 3}$ & 0.836 & 1.247 & 1.042 \\
\hline $\mathbf{2 0 0 3 - 0 4}$ & 0.761 & 1.070 & 0.815 \\
\hline $\mathbf{2 0 0 4 - 0 5}$ & 1.465 & 1.086 & 1.592 \\
\hline $\mathbf{2 0 0 5 - 0 6}$ & 1.072 & 1.303 & 1.397 \\
\hline $\mathbf{2 0 0 6 - 0 7}$ & 1.000 & 1.039 & 1.039 \\
\hline $\mathbf{2 0 0 7 - 0 8}$ & 1.000 & 1.170 & 1.170 \\
\hline $\mathbf{2 0 0 8 - 0 9}$ & 1.000 & 0.997 & 0.997 \\
\hline Mean & $\mathbf{1 . 0 1 0}$ & $\mathbf{1 . 1 1 0}$ & $\mathbf{1 . 1 2 1}$ \\
\hline
\end{tabular}

Note: - All Malmquist index averages are geometric means.

EFFch-Efficiency change; TECHch-Technological progress; TFPch-Total Factor Productivity change.

Source: Computed

Table 6

Sources of Productivity Growth in Essar Oil Ltd

\begin{tabular}{|c|c|c|c|}
\hline Year & EFFch & TECHch & TFPch \\
\hline $\mathbf{1 9 9 5 - 9 6}$ & 0.714 & 1.191 & 0.851 \\
\hline $\mathbf{1 9 9 6 - 9 7}$ & 0.464 & 1.024 & 0.476 \\
\hline $\mathbf{1 9 9 7 - 9 8}$ & 0.798 & 0.965 & 0.770 \\
\hline $\mathbf{1 9 9 8 - 9 9}$ & 0.776 & 1.370 & 1.064 \\
\hline $\mathbf{1 9 9 9 - 0 0}$ & 0.915 & 1.053 & 0.964 \\
\hline $\mathbf{2 0 0 0 - 0 1}$ & 0.781 & 1.178 & 0.920 \\
\hline $\mathbf{2 0 0 1 - 0 2}$ & 1.060 & 1.050 & 1.113 \\
\hline $\mathbf{2 0 0 2 - 0 3}$ & 0.584 & 1.445 & 0.844 \\
\hline $\mathbf{2 0 0 3 - 0 4}$ & 2.989 & 1.365 & 4.081 \\
\hline $\mathbf{2 0 0 4 - 0 5}$ & 3.522 & 0.831 & 2.926 \\
\hline $\mathbf{2 0 0 5 - 0 6}$ & 0.312 & 1.183 & 0.369 \\
\hline $\mathbf{2 0 0 6 - 0 7}$ & 1.229 & 1.105 & 1.358 \\
\hline $\mathbf{2 0 0 7 - 0 8}$ & 12.750 & 0.488 & 6.225 \\
\hline $\mathbf{2 0 0 8 - 0 9}$ & 1.182 & 1.690 & 1.996 \\
\hline Mean & $\mathbf{1 . 1 3 0}$ & $\mathbf{1 . 0 9 8}$ & $\mathbf{1 . 2 4 1}$ \\
\hline
\end{tabular}

Note: - All Malmquist index averages are geometric means.

EFFch-Efficiency change; TECHch-Technological progress; TFPch-Total Factor

Productivity change.

Source: Computed

Table 7

Sources of Productivity Growth in Reliance Industries Ltd

\begin{tabular}{|c|c|c|c|}
\hline Year & EFFch & TECHch & TFPch \\
\hline $\mathbf{1 9 9 5 - 9 6}$ & 0.943 & 1.191 & 1.123 \\
\hline $\mathbf{1 9 9 6 - 9 7}$ & 0.640 & 1.025 & 0.656 \\
\hline $\mathbf{1 9 9 7 - 9 8}$ & 1.403 & 0.956 & 1.342 \\
\hline
\end{tabular}


Productivity Growth in Indian Oil Refineries : Efficiency Improvement or Technical Improvement

\begin{tabular}{|c|c|c|c|}
\hline $\mathbf{1 9 9 8 - 9 9}$ & 0.764 & 1.349 & 1.030 \\
\hline $\mathbf{1 9 9 9 - 0 0}$ & 1.485 & 1.036 & 1.538 \\
\hline $\mathbf{2 0 0 0 - 0 1}$ & 1.324 & 1.283 & 1.700 \\
\hline $\mathbf{2 0 0 1 - 0 2}$ & 1.256 & 0.996 & 1.251 \\
\hline $\mathbf{2 0 0 2 - 0 3}$ & 0.756 & 1.362 & 1.029 \\
\hline $\mathbf{2 0 0 3 - 0 4}$ & 0.744 & 1.182 & 0.879 \\
\hline $\mathbf{2 0 0 4 - 0 5}$ & 0.951 & 1.176 & 1.118 \\
\hline $\mathbf{2 0 0 5 - 0 6}$ & 0.653 & 1.236 & 0.807 \\
\hline $\mathbf{2 0 0 6 - 0 7}$ & 0.921 & 1.041 & 0.959 \\
\hline $\mathbf{2 0 0 7 - 0 8}$ & 1.007 & 1.073 & 1.081 \\
\hline $\mathbf{2 0 0 8 - 0 9}$ & 0.712 & 1.309 & 0.932 \\
\hline Mean & $\mathbf{0 . 9 3 1}$ & $\mathbf{1 . 1 5 1}$ & $\mathbf{1 . 0 7 1}$ \\
\hline
\end{tabular}

Note: - All Malmquist index averages are geometric means. EFFch-Efficiency change ;

TECHch- Technological progress ;TFPch-Total Factor Productivity change.

Source: Computed

Table 8

Estimates of Annual Means of Total Factor Productivity Growth in oil refinery industry

\begin{tabular}{|c|c|c|c|}
\hline Year & EFFch & TECHch & TFPch \\
\hline $\mathbf{1 9 9 5 - 9 6}$ & 0.870 & 1.131 & 0.984 \\
\hline $\mathbf{1 9 9 6 - 9 7}$ & 0.858 & 0.939 & 0.806 \\
\hline $\mathbf{1 9 9 7 - 9 8}$ & 1.019 & 0.953 & 0.971 \\
\hline $\mathbf{1 9 9 8 - 9 9}$ & 0.951 & 1.328 & 1.263 \\
\hline $\mathbf{1 9 9 9 - 0 0}$ & 1.045 & 1.069 & 1.117 \\
\hline $\mathbf{2 0 0 0 - 0 1}$ & 0.988 & 1.218 & 1.203 \\
\hline $\mathbf{2 0 0 1 - 0 2}$ & 1.110 & 0.923 & 1.025 \\
\hline $\mathbf{2 0 0 2 - 0 3}$ & 0.830 & 1.293 & 1.073 \\
\hline $\mathbf{2 0 0 3 - 0 4}$ & 1.084 & 1.100 & 1.192 \\
\hline $\mathbf{2 0 0 4 - 0 5}$ & 1.260 & 0.980 & 1.235 \\
\hline $\mathbf{2 0 0 5 - 0 6}$ & 0.799 & 1.126 & 0.900 \\
\hline $\mathbf{2 0 0 6 - 0 7}$ & 0.994 & 1.077 & 1.071 \\
\hline $\mathbf{2 0 0 7 - 0 8}$ & 1.423 & 0.952 & 1.356 \\
\hline $\mathbf{2 0 0 8 - 0 9}$ & 0.983 & 1.163 & 1.143 \\
\hline Mean & $\mathbf{1 . 0 0 3}$ & $\mathbf{1 . 0 8 2}$ & $\mathbf{1 . 0 8 6}$ \\
\hline
\end{tabular}

Note: - All Malmquist index averages are geometric means. EFFch is efficiency change,

Source: Computed

TECHch is technological progress and TFPch is total factor productivity change.

Table 9

Estimates of Company-wise Means of Total Factor Productivity Growth in oil refinery industry

\begin{tabular}{|l|c|c|c|}
\hline \multicolumn{1}{|c|}{ Companies } & EFFch & TECHch & TFPch \\
\hline Bharat Petroleum Corporation Ltd & 0.998 & 1.004 & 1.001 \\
\hline Hindustan Petroleum Corporation Ltd & 0.992 & 1.021 & 1.013 \\
\hline Indian Oil Corporation Ltd & 0.971 & 1.048 & 1.017 \\
\hline Reliance Industries Ltd & 0.931 & 1.151 & 1.071 \\
\hline Mangalore Refinery and Petrochemicals Ltd & 1.000 & 1.155 & 1.155 \\
\hline Essar Oil Ltd & 1.130 & 1.098 & 1.241 \\
\hline Chennai Petroleum Corporation Ltd & 1.010 & 1.110 & 1.121 \\
\hline Mean & $\mathbf{1 . 0 0 3}$ & $\mathbf{1 . 0 8 2}$ & $\mathbf{1 . 0 8 6}$ \\
\hline
\end{tabular}

Note: - All Malmquist index averages are geometric means. EFFch-Efficiency change ; TECHchTechnological progress ; TFPch-Total Factor Productivity change. Source:Computed. 